\title{
Monitoring of concordance in growth hormone therapy
}

\author{
R R Kapoor, S A Burke, S E Sparrow, I A Hughes, D B Dunger, K K Ong, C L Acerini
}

Department of Paediatrics, Addenbrooke's Hospital, University of Cambridge, Cambridge, UK

Correspondence to:

Dr C L Acerini, Department of

Paediatrics, Addenbrooke's

Hospital, Hills Road, Cambridge

CB2 200, UK

cla22@cam.ac.uk

Accepted 31 July 2007 Published Online First

31 August 2007

\section{ABSTRACT}

Concordance with growth hormone (GH) therapy in 75 children was objectively assessed using data on GP prescriptions over 12 months. 23\% missed $>2$ injections/ week. Lower concordance was associated with longer duration on GH therapy $(p<0.005)$, lack of choice of delivery device $(p<0.005)$ and short prescription durations $(p<0.005)$, and predicted lower height velocities $(p<0.05)$.

Concordance with drug therapy is often poor in chronic non-life-threatening conditions such as growth hormone $(\mathrm{GH})$ deficiency. ${ }^{1}$ Motivation may be low as the benefits are not immediately apparent and daily subcutaneous injections may present a significant burden.

Concordance with GH therapy has been related to patient and family education, timing and location of education sessions, and the type of healthcare professional providing the education. ${ }^{2}{ }^{3}$ In a retrospective observational study we examined whether various differences in $\mathrm{GH}$ prescribing policies were associated with objectively measured treatment concordance and short-term growth outcomes.

\section{METHODS}

We collected data on $75 \mathrm{GH}$ deficient children receiving $\mathrm{GH}$ therapy who attended a regional paediatric endocrine clinic at Addenbrooke's Hospital, Cambridge during 1999-2003.

We sent a postal questionnaire to the children's general practitioners (GPs) who issued the $\mathrm{GH}$ prescriptions under a shared care agreement. Data on 11 patients were obtained from an outreach clinic where GH prescriptions were provided directly by a designated local consultant paediatrician. The questionnaire requested details on the number of issued prescriptions and the total $\mathrm{GH}$ dose (or number of vials/cartridges) issued with each prescription during three specific 12-month periods (1999-2000, 2000-2001 and 2002-2003). Most of the data returned by GPs was in the form of computerised printouts. We approached 66 GP practices and 58 replied (response rate $88 \%$ ).

$\mathrm{GH}$ devices used included automatic injection devices $(n=38)$, manual injection pen devices $(n=33)$ and needle-free injection devices $(n=4)$. According to a gradual change in clinic policy, children had been either allocated to a specific GH device by the nurse specialist or consultant, or had been offered a free choice of devices. All children and parents received training on GH delivery from one nurse specialist (SB). Patients were seen in the regional clinic every 4-6 months for assessment of height by the nurse specialists and review of $\mathrm{GH}$ doses.

\section{Concordance}

Concordance was objectively assessed in each child by comparing total expected GH usage as documented in the clinic records and letters to the total amount of GH prescribed by GPs during a 12-month period. From the expected daily dose (mg/day) (A), the expected annual $\mathrm{GH}$ requirement for each patient (B) was calculated. The number of issued prescriptions and the number of vials provided with each prescription enabled calculation of the total amount of $\mathrm{GH}$ prescribed by the GP over the same 12-month period (C). The annual deficit (D) in $\mathrm{GH}$ prescribed compared to that expected was calculated as $(\mathrm{D}=\mathrm{B}-\mathrm{C})$. The estimated number of missed injections per week was calculated as $(\mathrm{D} /[52 \times \mathrm{A}])$.

\section{Calculations and statistics}

Height standard deviation scores (SDS) were calculated by comparison with the UK 1990 growth reference. Cross-sectional analysis was performed using the first data entry from each of the 75 children. Associations with concordance were tested by using $\chi^{2}$ trend tests for categorical variables (choice of GH device, prescription duration) and by linear regression for continuous variables (age, duration of treatment and height velocity).

Longitudinal analysis was performed using 71 data points, taken once every 2 years from 31 of the children ( 22 children provided two data points and nine children provided three data points). Longitudinal analyses between changes in concordance, prescription duration and height velocity were performed by analysis of co-variance by adding subject name as a fixed factor.

Finally, using all data points, chronological changes from 1999 to 2003 in concordance, prescription duration and height velocity were tested using $\chi^{2}$ trend tests for categorical variables, and linear regression for continuous variables. Analyses were performed using SPSS version 11.0

\section{RESULTS}

\section{Cross-sectional data analysis}

Cross-sectional data were available on $75 \mathrm{GH}$ deficient children, with median (interquartile range) age 12.3 years (8.9-14.8), duration of $\mathrm{GH}$ treatment 1.9 years $(1.2-4.0)$ and GH dose $0.8 \mathrm{mg} /$ $\mathrm{kg} /$ day $(0.7-1.2) ; 63 \%(\mathrm{n}=47)$ were male and $60 \%$ $(\mathrm{n}=45)$ had multiple hormone deficiency

More than $>1$ injection/week was missed by 39\% $(29 / 75)$ of the children, and $23 \%(17 / 75)$ missed $>2$ injections/week. Table 1 shows that factors associated with lower concordance were a longer duration on GH therapy $(p<0.005)$, lack of choice over $\mathrm{GH}$ device $(\mathrm{p}<0.005)$ and short duration $(<4$ weeks) of $\mathrm{GH}$ prescriptions $(p<0.005)$. Concordance was 
Table 1 Cross-sectional analysis of estimated GH compliance (frequency of missed injections) in 75 children

\begin{tabular}{|c|c|c|c|c|}
\hline & \multicolumn{4}{|c|}{ Frequency of missed injections } \\
\hline & Nil & Up to $1 /$ week & $>1-2 /$ week & $>2 /$ week \\
\hline $\begin{array}{l}\% \text { Of total } \\
\text { group (n) }\end{array}$ & $36 \%(27)$ & $25 \%(19)$ & $16 \%(12)$ & $23 \%(17)$ \\
\hline Age (years) & 12.3 & 11.9 & 11.9 & 14.2 \\
\hline $\begin{array}{l}\text { Duration of GH } \\
\text { therapy (years) } \dagger\end{array}$ & 1.6 & 1.8 & 2.8 & $4.3^{* *}$ \\
\hline $\begin{array}{l}\text { Given choice of } \\
\text { GH device }\end{array}$ & $81 \%$ & $68 \%$ & $58 \%$ & $23 \% * *$ \\
\hline $\begin{array}{l}\text { Prescription duration } \\
<4 \text { weeks }\end{array}$ & $10 \%$ & $6 \%$ & $27 \%$ & $50 \% * *$ \\
\hline $\begin{array}{l}\text { Height velocity } \\
(\mathrm{cm} / \text { year): }\end{array}$ & 7.8 & 6.6 & 7.5 & $4.6^{*}$ \\
\hline $\begin{array}{l}\text { Height velocity } \\
\text { (SDS/year): }\end{array}$ & 0.47 & 0.47 & 0.42 & $0.05^{*}$ \\
\hline
\end{tabular}

${ }^{*} p<0.05,{ }^{* *} p<0.005$ for linear trends.

† Similar results are seen after adjustment for age (not shown).

\$Adjusted for age and duration of GH therapy.

Data are \% of all subjects (n) or medians.

unrelated to age or initial height SDS. Lower concordance was associated with reduced height velocity $(p<0.005)$; this association remained significant after adjustment for duration of GH therapy $(\mathrm{p}<0.05$; table 1$)$, and the effect was particularly evident during the first 2 years of GH therapy ( $p<0.05$; data not shown).

Among the 46 children who had been given a free choice of $\mathrm{GH}$ device, there were no significant differences in concordance or height velocity according to type of GH device (data not shown).

\section{Longitudinal data analysis}

A total of 31 children provided 71 repeated data points at intervals of 2 years between 1999 and 2003. In longitudinal withinindividual analyses, prescription durations increased by (mean (SE)) 0.57 (0.21) weeks/year $(\mathrm{p}=0.01)$. Avoidance of prescription durations of $<4$ weeks was associated with an increase of 1.12 (0.39) injections/week $(p=0.005)$ and a trend towards a rise in height velocity of $0.20(0.13)$ SDS/year $(p=0.1)$.

\section{Chronological analysis}

Analyses of all 115 data points from the 75 children according to chronological year showed significant trends towards older age (but not longer duration of GH therapy), longer duration of prescriptions, improved concordance and increased growth responses to treatment (table 2 ).

\section{DISCUSSION}

Our study shows that poor concordance with GH therapy is frequent in children with GH deficiency. Even so, we have likely underestimated the prevalence of poor concordance, as we could not take into account the accidental or deliberate wastage of $\mathrm{GH}$. Furthermore, we acknowledge that issuing of prescriptions by the GP does not equate to encashment and administration of GH.

However, these proportions are consistent with other studies using other objective assessments. From data on encashed prescriptions, Hunter et al found that $33 \%$ of their patients received less than $80 \%$ of their expected $\mathrm{GH}$ dose. ${ }^{1}$ Similarly, Desrosiers et al reported that $15-24 \%$ of 630 children missed more than three injections per month. ${ }^{4}$

The need for a long-term commitment to daily subcutaneous injections has major implications for the child and the family. In our study, decreasing concordance was associated with a longer duration on GH therapy. In recent years, a number of new injection delivery devices have been introduced which have
Table 2 Chronological changes in GH prescribing patterns, compliance and growth responses from 1999 to 2003

\begin{tabular}{lllll}
\hline & $\begin{array}{l}\mathbf{1 9 9 9} \\
\mathbf{n = 3 5}\end{array}$ & $\begin{array}{l}\mathbf{2 0 0 1} \\
\mathbf{n = 3 0}\end{array}$ & $\begin{array}{l}\mathbf{2 0 0 3} \\
\mathbf{n = 4 9}\end{array}$ & $\mathbf{p}$ Trend \\
\hline Age (years) & 11.0 & 13.5 & $13.7^{*}$ & 0.049 \\
Years on GH therapy & 2.1 & 4.0 & 2.8 & 0.9 \\
Given choice of GH device & $53 \%$ & $53 \%$ & $68 \%^{*}$ & 0.3 \\
Prescription duration (weeks) & 4 & 5 & $7^{*}$ & 0.02 \\
$>2$ injections missed/week & $36 \%$ & $17 \%$ & $8 \%^{* *}$ & 0.003 \\
Height velocity (cm/year) $\dagger$ & 5.4 & 5.0 & $7.0^{*}$ & 0.03 \\
Height velocity (SDS/year) $\dagger$ & 0.11 & 0.20 & $0.45^{* *}$ & 0.005 \\
\hline
\end{tabular}

${ }^{*} p<0.05$, ** $p<0.005$ for 2003 vs 1999.

$\uparrow$ Adjusted for age and duration of GH therapy.

Data are medians or \% (n) of each year group.

simplified the drug administration process. However, in our study concordance did not differ between types of injection device. Rather, a free choice of injection device was associated with better concordance. One earlier study reported that choice of GH device had no effect on concordance. ${ }^{5}$ Those investigators studied the effect of a change in their clinic policy in 165 children. Interestingly, levels of concordance were already high (89\%) in their group given no choice of device (before December 2000). However, in their study, patient satisfaction appeared to be higher in those patients who had been offered a choice of device.

We found that concordance was positively related to duration of the GH prescription given by the GP. Short GH prescription duration and consequently more frequent prescription collections and pharmacy visits could have an adverse impact on family routine and increase the risk of $\mathrm{GH}$ supplies running out before collection of the next prescription. Following interim analyses of our study in 2000/1, we gradually extended free choice of GH devices to all new patients, and also encouraged GPs to avoid short prescription durations. While these are uncontrolled observational data, these interventions appear to have helped to increase both concordance and growth responses.

In conclusion, objective assessment of prescription data in a regional clinic setting revealed a high prevalence of poor concordance with GH therapy. As in other studies, poor concordance was associated with a reduction in height velocity. ${ }^{14}$ Our study identified a number of factors which influenced concordance, including choice of $\mathrm{GH}$ injection device and $\mathrm{GH}$ prescription duration. Identification of these factors informed our interventions to improve concordance and treatment responses in our clinic.

Acknowledgements: We are very grateful and indebted to Dr Nandu Thalange, Consultant Paediatrician at the Norfolk and Norwich University Hospital and our colleagues in general practice from Cambridge and the surrounding areas who assisted us with the collection of the $\mathrm{GH}$ prescription data.

Funding: None.

Competing interests: DBD, IAH, KO and CLA have either received research funding support and/or honoraria for speaking at meetings or have served on the advisory boards of one or more the following pharmaceutical companies who manufacture and sell human recombinant growth hormone: Novo Nordisk, Pfizer, Ipsen, Eli Lilly and Ferring.

\section{REFERENCES}

1. Hunter I, deVries C, Morris A, et al. Human growth hormone therapy: poor adherence equals poor growth. Arch Dis Child 2000;82(Suppl 1):28.

2. Hindmarsh PC, Brook CG. Compliance with growth hormone treatment - is it a problem? Horm Res 1999;51(Suppl 3):104-8.

3. Stanhope R, Moyle L, Mac Swiney M. Patient knowledge and compliance with growth hormone treatment. Arch Dis Child 1993;68(4):525.

4. Desrosiers $\mathbf{P}, \mathrm{O}^{\prime}$ Brien F, Blethen $\mathrm{S}$. Patient outcomes in the GHMonitor: the effect of delivery device on compliance and growth. Pediatr Endocrinol Rev 2005;2(Suppl 3):327-31

5. Wickramasuriya BP, Casey A, Akhtar $S$, et al. Factors determining patient choice of device for GH therapy. Horm Res 2006;65(1):18-22. 